\title{
Obturator Externus Muscle
}

National Cancer Institute

\section{Source}

National Cancer Institute. Obturator Externus Muscle. NCI Thesaurus. Code C33191.

A striated muscle located on the anterior surface of the pelvis, with its origin on the obturator foramen and obturatory membrane and insertion on the trochanteric fossa of the femur, which functions to laterally rotate the femur. 